Original Research Article

\title{
A comparative evaluation of structured and unstructured forms of viva voce for internal assessment of undergraduate students in Pharmacology
}

\author{
Tejas M. Khakhkhar*, Neelesh Khuteta, Gurudas Khilnani
}

Department of Pharmacology, Gujarat Adani Institute of Medical Sciences, Bhuj, Gujarat, India

Received: 18 December 2018 Accepted: 10 January 2019

*Correspondence to: Dr. Tejas M. Khakhkhar, Email: tejaskhakhar@gmail.com

Copyright: (C) the author(s), publisher and licensee Medip Academy. This is an openaccess article distributed under the terms of the Creative Commons Attribution NonCommercial License, which permits unrestricted noncommercial use, distribution, and reproduction in any medium, provided the original work is properly cited.

\begin{abstract}
Background: The study was designed to identify value of structured viva (SV) as an assessment tool, to ascertain its correlation with unstructured viva (UV) and to find relationship between viva and theory examination results.

Methods: This prospective and observational study was conducted on a total of 135 students of the $2^{\text {nd }}$ professional MBBS. All students faced two viva sessions (SV and UV), each of 10 marks on same topics in general pharmacology and autonomic nervous system. Time limit per student was 10 minutes. SV was conducted on pre-validated, standardized cards $(n=40)$ with 5 questions in each card and 0.5 marks of each question. By draw of lots to be performed by students themselves, each student was given 4 cards. One week prior to the viva, the theory examination of 40 marks on same topics was conducted.
\end{abstract}

Results: The mean marks of all students in SV $(3.46 \pm 1.44)$ were significantly lower $(\mathrm{P}<0.0001)$ than those of UV $(4.61 \pm 2.02)$. There was significant less deviation of mean marks in all groups of SV $(\mathrm{P}<0.05)$. The mean percentage marks of SV $(34.63 \pm 14.37 \%)$ had similarities with results of theory examination $(34.67 \pm 10.49 \%)(\mathrm{P}=0.9720)$, while the difference between mean percentage marks of UV $(46.15 \pm 20.19 \%)$ and theory was statistically highly significant (P $<0.0001)$.

Conclusions: SV increases objectivity and reduces subjectivity as compared to UV because of similar pattern of questions, difficulty levels and standardised scoring system. SV provides an opportunity to measure how well students can apply knowledge. Thus, SV can be used for formative and summative assessment.

Keywords: Assessment tool, Pharmacology, Structured viva, Viva voce

\section{INTRODUCTION}

The learning cycle is a triad of educational objectives, instructional methodology and assessment. ${ }^{1}$ Amongst these, assessment is a critical issue. ${ }^{2}$ Viva voce is an important format of assessment that allows probing of breadth and depth of the knowledge. ${ }^{3}$ Joughin defined the viva examination as "assessment in which a student's response to the assessment task is verbal, in the sense of being expressed or conveyed by speech instead of writing. ${ }^{44}$ Recent studies have shown that in its traditional mode it is riddled with flaws and might not be appropriate for the assessment of student's interactive skills and higher cognitive functions. ${ }^{5}$ The factors which affect the oral ratings include inter-examiner variability including halo effect (a judgment of one attribute influences judgments of others) and reliability of examiner's evaluation in grading the students, lack of standardization of time allotted for viva per student, the extent of course covered, student's self-confidence, anxiety, concept discussion by student 
and examiner's relative dominance. ${ }^{6-12}$ Obviously, to utilize this mode of evaluation more effectively, it requires reorientation and careful construction of questions to test higher cognitive domains. , $^{3,13}$

In order to overcome, the biases in the conventional format of assessment, structured oral and practical examination has been formatted by various workers. ${ }^{3,8,14}$

Nevertheless, this modified format of oral assessment may provide an equal opportunity to judge the knowledge and problem-solving ability of every student appearing in the exams, and therefore, may prove to be more reliable in terms of minimizing the bias and reducing the luck factor. $^{15}$

This study was designed to identify value of structured viva as an assessment tool and to ascertain its correlation with unstructured viva voce. It was also aimed at finding relationship, if any between structured viva and theory examination results.

\section{METHODS}

This was a prospective and observational study was conducted on students of the $2^{\text {nd }}$ professional MBBS in the Department of Pharmacology, Adani Institute of Medical Sciences, Bhuj, Gujarat, India after departmental and Institutional Ethics Committee permissions. Written informed consent was obtained from the participants. Thus, a total of 135 students were included in the study.

All the students participating in the study were randomized to participate in two viva voce sessions on same topics-one structured viva (SV) and another unstructured or conventional viva (UV), each of 10 marks on topics in General Pharmacology (GP) and Autonomic Nervous System (ANS). The time limit for both viva was fixed to 10 minutes. The marks of structured viva were not included in the internal assessment and considered only for study purpose.

For conducting structured viva, total 40 cards, 20 from GP and 20 from ANS with 5 questions in each card of increasing difficulty levels were prepared and prevalidated by three subject experts. The cards were standardized with respect to time allocation and topics covered for each student by a pilot study done on 15 students of senior batch. Based on which, it was decided to give 4 cards ( 2 from GP and 2 from ANS) to each student by draw of lots to be performed by students themselves. The examiner taking SV was provided with standardized answer-sheet and mark-sheet in which, each correct answer by student was considered 0.5 marks. The theory examination of 40 marks including objective questions, short answers and short notes on same topics was conducted one week prior to the viva.

A questionnaire, to assess the perception of students regarding SV was prepared which included questions based on Likert scale. Opinion of faculty involved in preparing viva cards and conducting examination was also taken after completion of viva.

For comparisons, all 135 students were divided into three groups, each of 45 students according to the marks obtained in structured viva. In which, group A of 45 students obtaining lowest marks in SV, group B of 45 students having marks in middle range in SV and group $\mathrm{C}$ of 45 students obtaining highest marks in SV.

Statistical analysis was performed by GraphPad Prism software version 7.01 applying paired t-test and Pearson correlation coefficient. P-value $\leq 0.05$ was considered as significant.

\section{RESULTS}

The mean marks of all 135 students in SV $(3.46 \pm 1.44)$ were significantly lower $(\mathrm{P}<0.0001)$ than those of UV $(4.61 \pm 2.02)$. Similar trends were seen in group A $(1.96 \pm 0.74$ vs $3.77 \pm 1.79)$, group B $(3.46 \pm 0.42$ vs $4.54 \pm 1.93)$ and group $C(4.98 \pm 0.95$ vs $5.53 \pm 1.97)$. Thus, overall less marks were obtained by students in structured viva compared to unstructured viva. In fact, such difference in marks was found highest in group $\mathrm{A}(\mathrm{P}<0.0001)$, then in group $\mathrm{B}(\mathrm{P}=0.0003)$ and group $\mathrm{C}(\mathrm{P}=0.0350)$ (Table 1 , Figure 1).

Table 1: Mean marks obtained in structured and unstructured VIVA and statistical significance.

\begin{tabular}{|ll|lll|}
\hline Group & $\begin{array}{l}\text { Students with chronological marks in } \\
\text { structured viva }\end{array}$ & $\begin{array}{l}\text { Mean } \pm \text { SD marks } \\
\text { in structured viva }\end{array}$ & $\begin{array}{l}\text { Mean } \pm \text { SD marks in } \\
\text { unstructured viva }\end{array}$ & \begin{tabular}{c} 
P value \\
\hline All students
\end{tabular} \\
\hline Group A & 1 to 135 & $3.46 \pm 1.44$ & $4.61 \pm 2.02$ & $<0.0001$ \\
\hline Group B & 46 to 90 & $1.96 \pm 0.74$ & $3.77 \pm 1.79$ & $<0.0001$ \\
\hline Group C & 91 to 135 & $3.46 \pm 0.42$ & $4.54 \pm 1.93$ & 0.0003 \\
\hline
\end{tabular}




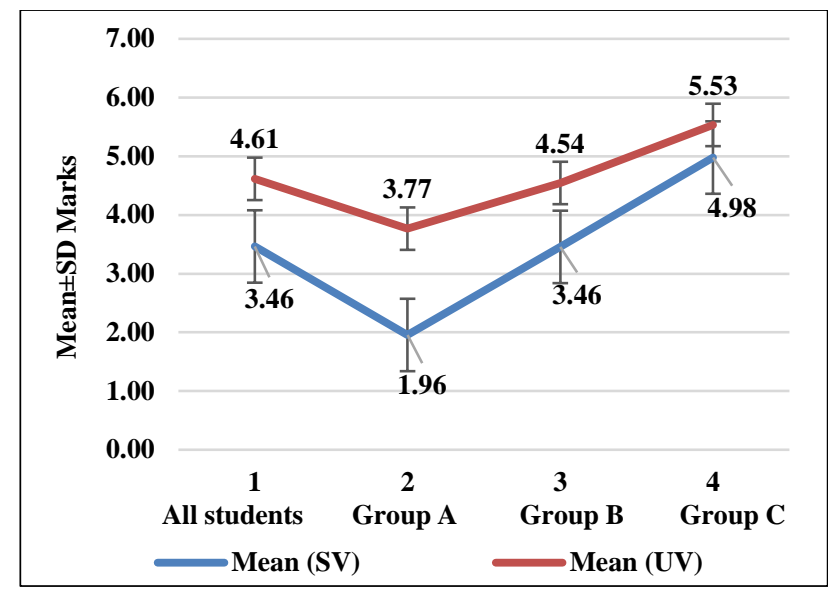

Figure 1: Correlation between marks obtained in structured and unstructured viva.

There was less deviation of mean marks in all groups when structured format of viva was used (Figure 2).

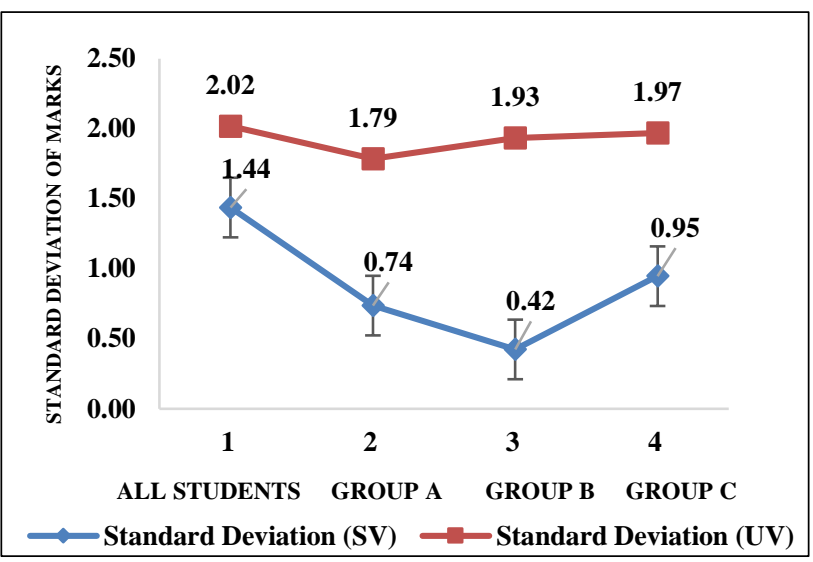

Figure 2: Deviation of mean marks in structured and unstructured viva.
This was also found statistically significant $(\mathrm{P}<0.05)$. This indicated that structuring a viva voce examination discriminates clearly between high scorers from lower ones. However, a linear correlation $(r=0.5211)$ was found between highest to lowest marks both in SV and UV groups. The greatest value of structuring was found in identifying poor scorers (group A) as compared to UV. It did not matter to high scorers (group C) (Figure 1).

When the mean percentage marks of theory examination $(34.67 \pm 10.49 \%)$ were compared with mean percentage marks of SV $(34.63 \pm 14.37 \%)$ and UV $(46.15 \pm 20.19 \%)$ (Figure 3), the difference between SV and theory mean percentage marks was not statistically significant $(\mathrm{P}=0.9720)$, while the difference between UV and theory mean percentage marks was statistically highly significant ( $\mathrm{P}<0.0001)$. However, positive correlation was observed between Theory and SV $(\mathrm{r}=0.5535)$ as well as Theory and $\mathrm{UV}(\mathrm{r}=0.7313)$ (Table 2, Figure 4).

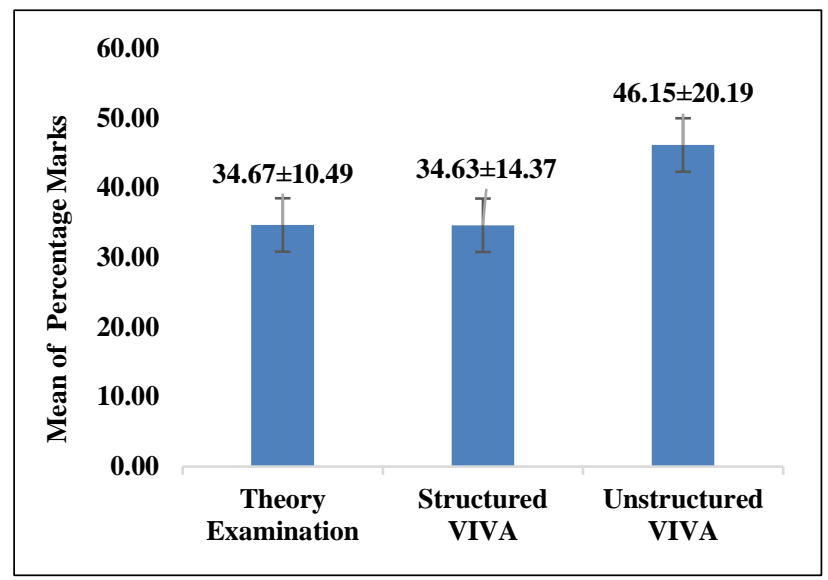

Figure 3: Comparison of mean percentage marks between theory, structured viva and unstructured viva.

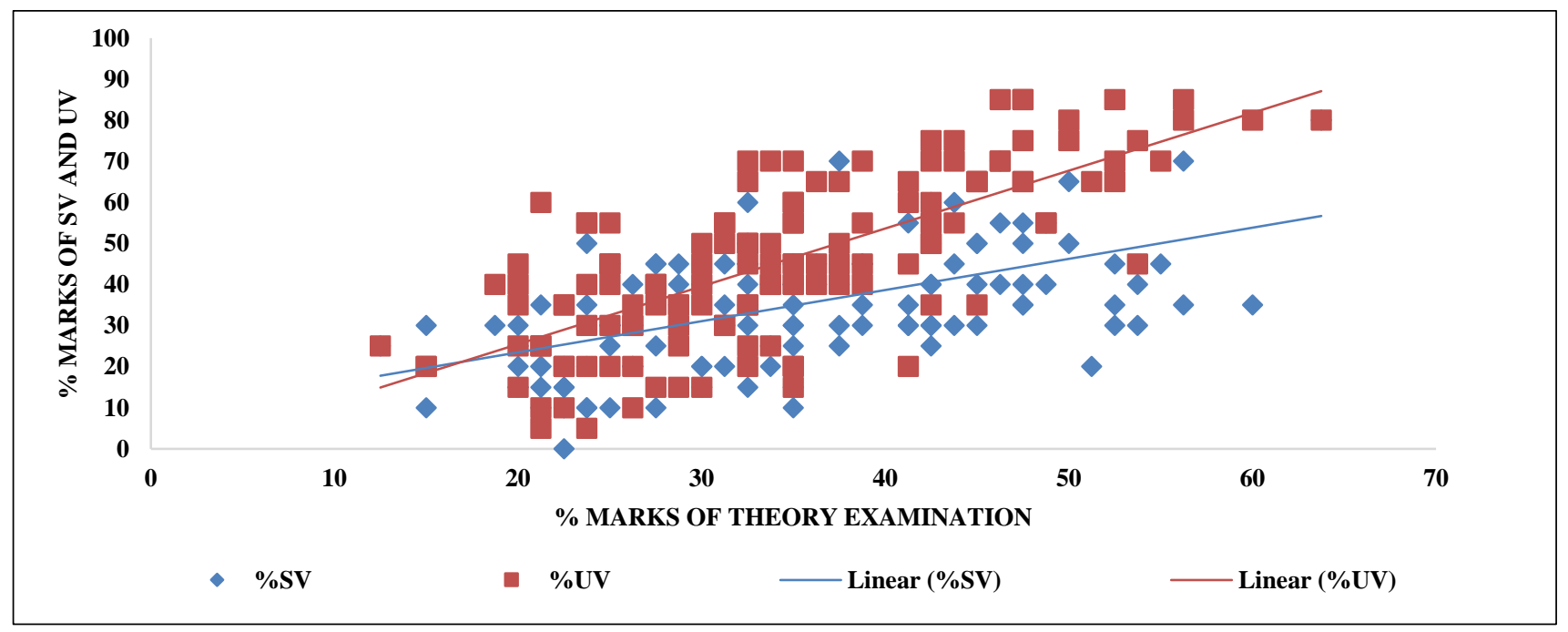

Figure 4: Correlation between percentage marks of theory exam vs. percentage marks of SV and UV. 
Table 2: Comparison between mean of percentage marks of theory and two formats of viva.

\begin{tabular}{|llllll|}
\hline Examination formats to compare & Mean \pm SD of percentage marks & \multicolumn{2}{l|}{ Paired $\mathbf{t}(\mathbf{d}=\mathbf{1 3 4})$} & $\mathbf{P}$ value & $\boldsymbol{r}$ \\
\hline Theory and SV & $34.67 \pm 10.49$ & $34.63 \pm 14.37$ & 0.0352 & 0.9720 & 0.5535 \\
\hline Theory and UV & $34.67 \pm 10.49$ & $46.15 \pm 20.19$ & 9.2534 & $<0.0001$ & 0.7313 \\
\hline SV and UV & $34.63 \pm 14.37$ & $46.15 \pm 20.19$ & 7.5808 & $<0.0001$ & 0.5211 \\
\hline
\end{tabular}

\section{Student's response to questionnaire on $S V$}

Total 119 students responded to questionnaire as shown in Table 3. Majority of the student's favoured structured format of viva as compared to UV. The students agreed that viva environment was conducive $(64.71 \%)$, this format covered all topics $(52.94 \%)$, appropriate time was given for answering questions (61.34\%), questions asked were relevant to topics $(68.91 \%)$, uniformity was maintained among students $(59.66 \%)$, examiner related bias was less (46.22\%), number of questions were adequate $(56.30 \%)$, and they prefer this format to conventional viva (51.26\%). However, $36.97 \%$ disagreed that there was less variability in this format (Table 3).

Table 3: Student's response to questionnaire and mean score of each statement.

\begin{tabular}{|lllllll|}
\hline Statement & $\begin{array}{l}\text { Strongly } \\
\text { disagree }\end{array}$ & $\begin{array}{l}\text { Disagree } \\
(\%)\end{array}$ & $\begin{array}{l}\text { Neutral } \\
(\%)\end{array}$ & $\begin{array}{l}\text { Agree } \\
(\%)\end{array}$ & $\begin{array}{l}\text { Strongly } \\
\text { agree }(\%)\end{array}$ & *Mean \pm SD \\
\hline Conducive viva environment & $0(0)$ & $6(5.04)$ & $36(30.25)$ & $27(22.69)$ & $50(42.02)$ & $4.02 \pm 0.97$ \\
\hline This format covered all topics & $1(0.84)$ & $9(7.56)$ & $46(38.66)$ & $28(23.53)$ & $35(29.41)$ & $3.73 \pm 1.00$ \\
\hline $\begin{array}{l}\text { Appropriate time was given for } \\
\text { answering questions }\end{array}$ & $2(1.68)$ & $10(8.40)$ & $33(27.73)$ & $30(25.21)$ & $43(36.13)$ & $3.83 \pm 1.11$ \\
\hline There was less variability in this format & $12(10.08)$ & $32(26.89)$ & $43(36.13)$ & $20(16.81)$ & $10(8.40)$ & $2.82 \pm 1.14$ \\
\hline Questions asked were relevant to topics & $0(0)$ & $5(4.20)$ & $31(26.05)$ & $38(31.93)$ & $44(36.97)$ & $3.99 \pm 0.97$ \\
\hline $\begin{array}{l}\text { Uniformity was maintained Among } \\
\text { students }\end{array}$ & $7(5.88)$ & $8(6.72)$ & $33(27.73)$ & $31(26.05)$ & $40(33.61)$ & $3.75 \pm 1.17$ \\
\hline Examiner related bias was less & $6(5.04)$ & $13(10.92)$ & $35(29.41)$ & $16(13.45)$ & $39(32.77)$ & $3.33 \pm 1.56$ \\
\hline Number of questions were adequate & $4(3.36)$ & $7(5.88)$ & $40(33.61)$ & $24(20.17)$ & $43(36.13)$ & $3.77 \pm 1.15$ \\
\hline I prefer this format to conventional viva & $8(6.72)$ & $14(11.76)$ & $33(27.73)$ & $28(23.53)$ & $33(27.73)$ & $3.46 \pm 1.33$ \\
\hline
\end{tabular}

\section{DISCUSSION}

Most of the medical colleges in India, still conduct the viva voce by conventional (unstructured) method. Few studies, mostly in the subjects of first MBBS, have been done to know the perception and performance of students towards structured viv. ${ }^{16-18}$ This study was conducted with the objective to further delineate and clarify the role of SV in comparison with UV in evaluation of UG students in $2^{\text {nd }}$ MBBS internal assessment of pharmacology and to understand their association with theory examination.

It was observed that by applying structured format of viva the differentiation between good performers and poor performers becomes easy. Waseem $\mathrm{N}$ et al, also showed that it was not difficult to discriminate good and average performers in SV compared to UV. ${ }^{19}$ Structuring further reduces deviation in marks which may reflect the reliability of the format. The similar findings were noted by Verma A et al. ${ }^{18}$

While other studies have shown no correlation between theory and viva or practical examination, the present study showed positive correlation between theory and SV marks $(\mathrm{r}=0.5535)$ as well as between theory and UV marks $(\mathrm{r}=0.7313)^{6,20,21}$ Also, mean percentage marks of theory and SV has similarities in results $(\mathrm{P}=0.9720)$. However, significant difference was found in mean percentage marks of theory and UV ( $\mathrm{P}<0.0001)$. This indicates consistency of SV as well as reduced 'halo effect' compared to UV.

In the present study, the student's perspective regarding SV was encouraging. Greater proportion of the students (60$70 \%$ ) considered SV to be more conducive, appropriately timed for understanding and responding to questions, relevant to topics and greater coverage of topics with provision of equal opportunity to all students. Similar findings were reported in other studies done in the subjects of physiology, anatomy, biochemistry and microbiology. ${ }^{17,22-24}$

About one third (44 (36.97\%)) of the students disagreed that there was less variability in this format. The reason for that could be the limited number (four) of cards available to them. This can be minimised either by structuring cards in a manner covering most of the topics in a smaller number 
of total cards, considering same cards for all students or by increasing the time for each student to allow a greater number of cards to respond. The latter is more demanding in the form of resources and examiners.

This emphasises the need of extensive ground work, training of teachers, orientation and practice of students by mock exams.

The opinion of all faculty involved in the study regarding overall process of structured viva was favourable than that for conventional viva voce. They found that preparation of questions and model answers were labour intensive. This was however, compensated by reduction in time spent on conducting viva. Once finalized, the same SV material can be used for subsequent years for formative assessment also. A large sample size than used in present study would be needed to substantiate this trend.

\section{CONCLUSION}

Structured viva voce increases objectivity and reduces subjectivity as compared to conventional pattern of unstructured viva. This is because, in SV, use of similar pattern of questions with similar difficulty levels, standardised scoring system and equal time allotted to each student minimize the uncertainties unique to UV. SV provides an opportunity to measure how well students can apply knowledge apart from recall and also motivates many students to prepare subject matter better than for unstructured viva. Thus, SV can be used for formative and summative assessment.

\section{Funding: No funding sources}

Conflict of interest: None declared

Ethical approval: The study was approved by the Institutional Ethics Committee

\section{REFERENCES}

1. Mahajan AS, Shankar N, Tandon OP. The comparison of OSPE with conventional physiology practical assessment. J Int Assoc Med Sci Educ. 2004;14:54-7.

2. Jindal P, Khurana G. The opinion of post graduate students on objective structured clinical examination in Anaesthesiology: A preliminary report. Ind J Anaes. 2016;60(3):168.

3. Khilnani AK, Charan J, Thaddanee R, Pathak RR, Makwana S, Khilnani G. Structured oral examination in pharmacology for undergraduate medical students: Factors influencing its implementation. Ind $\mathbf{J}$ Pharmacol. 2015;47(5):546.

4. Joughin G. Dimensions of oral assessment. Assess Evaluation Higher Edu. 1998;23(4):367-78.

5. Singh T. Student assessment: Issues and dilemmas regarding objectivity. Natl Med J India. 2012;25(5):287-90.

6. Torke S, Abraham RR, Ramnarayan K, Asha K. The impact of viva-voce examination on students performance in theory component of the final summative examination in physiology. J Physiol Pathophysiol. 2010;1(1):10-2.

7. Bahannan SA. Reliability of Examiners' Evaluations of Oral Presentations in Fixed Prosthodontics. IOSRJDMS. 2014;13(3):28-31.

8. Dhasmana DC, Bala S, Sharma R, Sharma T, Kohli S, Aggarwal N,et al. Introducing structured viva voce examination in medical undergraduate pharmacology: a pilot study. Ind J Pharmacol. 2016;48(1):52.

9. Gupta P, Dewan P, Singh T. Objective structured clinical examination (OSCE) revisited. Ind Pediatrics. 2010;47(11):911-20.

10. Haque M, Yousuf R, Baker SA, Salam A. Assessment in undergraduate medical education: Bangladesh perspectives. Bangladesh J Med Sci. 2013;12(4):35763.

11. Memon MA, Joughin GR, Memon B. Oral assessment and postgraduate medical examinations: establishing conditions for validity, reliability and fairness. Adv Heal Sci Edu. 2010;15(2):277-89.

12. Cobourne MT. What's wrong with the traditional viva as a method of assessment in orthodontic education? J Orthodontics. 2010;37(2):128-33.

13. Garcia-Jardon ME, Blanco-Blanco EV, Bhat VG, Vasaikar SD, Kwizera EN, Stepien A. Correlation between different PBL assessment components and the final mark for MB ChB III at a rural South African university. Afri J Heal Professions Edu. 2009;1(1):124.

14. Malhotra SD, Shah KN, Patel VJ. Objective structured practical examination as a tool for the formative assessment of practical skills of undergraduate students in pharmacology. J Edu Heal Promotion. 2013;2.

15. Smith LJ, Price DA, Houston IB. Objective structured clinical examination compared with other forms of student assessment. Arch Dis Childhood. 1984;59(12):1173-6.

16. Rehman R, Syed S, Iqbal A, Rehan RR. Perception and performance of medical students in objective structured practical examination and viva voce. Pak $\mathbf{J}$ Physiol. 2012;8(2):33-6.

17. Shenwai MR, Patil KB. Introduction of structured oral examination as a novel assessment tool to first year medical students in physiology. J Clin Diagnostic Res: JCDR. 2013;7(11):2544.

18. Verma A, Mahajan N, Jasani K, Patel J. Evaluation and comparison of result: conventional viva vs structured viva. Glob Res Anal. 2013;2:188-9.

19. Waseem N, Iqbal K. Importance of structured viva as an assessment tool in anatomy. J Univ Med Dent Coll 2016;7(2):29-34.

20. Ghosh A, Mandal A, Das N, Tripathi SK, Biswas A, Bera T. Student's performance in written and vivavoce components of final summative pharmacology examination in MBBS curriculum: a critical insight. Ind J Pharmacol. 2012;44(2):274.

21. Patel B, Kubavat A, Piparva K. Correlation of student's performance in theory and practical of final summative pharmacology examination in MBBS 
curriculum: A critical insight. National J Physiol Pharmacy Pharmacol. 2013;3(2):171.

22. Kshirsagar SV, Fulari SP. Structured oral examination-student's perspective. Anatom Karnataka. 2011;5(2):28-31.

23. Puppalwar PV, Rawekar A, Chalak A, Dhok A, Khapre M. Introduction of objectively structured vivavoce in formative assessment of medical and dental undergraduates in biochemistry. J Res Med Edu Ethics. 2014;4(3):321-5.

24. Mudey DG, Damke S, Tankhiwale N, Mudey A. Assessment of perception for objectively structured viva voce amongst undergraduate medical students and teaching faculties in a medical college of central India. Int J Res Med Sci. 2016;4:2951-4.

Cite this article as: Khakhkhar TM, Khuteta N, Khilnani G. A comparative evaluation of structured and unstructured forms of viva voce for internal assessment of undergraduate students in Pharmacology. Int J Basic Clin Pharmacol 2019;8:616-21. 